\title{
Analisis Kelayakan Struktur Dermaga IV Pelabuhan Malundung Kota Tarakan untuk Kapasitas Mobil Crane Bongkar Muat
}

\author{
Edy Utomo \\ Program Studi Teknik Sipil, FT UBT, Tarakan \\ e-mail: edyutomo99@gmail.com
}

Received 11 November 2020; Reviewed 26 January 2021; Accepted 01 April 2021

Journal Homepage: http://jurnal.borneo.ac.id/index.php/borneoengineering

\begin{abstract}
Malundung Port, which is estimated to have been built around the 1970s, is one of the largest ports in the territory of North Borneo Province. There is one wharf is approximately 40 years old, which will be used as the loading and unloading area for Gas Pipes, before the pipes are distributed to several drilling points. One of the loading and unloading methods frequently proposed by the material supply side is to place a Mobile Crane at the top of the pier, with a Crane capacity of 165 tons. Based on this, this study tries to provide alternative solutions in making decisions regarding the method used for loading and unloading the pipe. However, it should be preceded by an investigation analysis study of force against the pier structure. The analytical method used is the direct observation method of the jetty construction and structural modeling using FEA (Finite Element Analysis). The Model will be made into 2 forms of Crane and Trailer position conditions which will then be analyzed the results of the forces that occur from each approach condition. Based on this method, this study concludes that the crane with a capacity of 165 tons and the Trailer cannot be used simultaneously on the pier, as well as carry out pipe loading and unloading activities. This is due to the failure of the beam system under the floor of the pier, even though the conditions of deformation and compression stress are still within safe limits. While the visual observations indicate some catastrophic failure of the system Beams, Pile Cap, and Floor Plates Pier in the form of large cracks that provide high corrosion impact on the steel reinforcement elements. Therefore, Pier IV needs to be given a construction revitalization to be able to serve loading and unloading activities to the fullest.
\end{abstract}

Keywords: Jetty, FEA, Port, Tarakan, Coastal Areas.

\begin{abstract}
Abstrak
Pelabuhan Malundung, yang diperkirakan telah dibangun sekitar tahun 1970-an merupakan saalah satu Pelabuhan terbesar yang berada di wilayah Provinsi Kalimantan Utara. Terdapat salah satu Dermaga yang telah berusia kurang lebih 40 tahun, yang akan dipergunakan sebagai daerah bongkar muat Pipa Gas, sebelum Pipa tersebut didistribusikan ke beberapa titik pengeboran. Salah satu metode bongkar muat yang sering diajukan oleh pihak suplai material adalah dengan meletakkan Mobil Crane pada bagian atas Dermaga, dengan Kapasitas Crane sebesar 165 Ton. Berdasarkan hal tersebut, penelitian ini mencoba memberikan solusi alternatif dalam pengambilan keputusan terkait metode yang digunakan untuk bongkar muat pipa tersebut. Namun, perlu didahului oleh kajian analisis investigasi kekuatan terhadap Struktur Dermaga tersebut. Metode analisis yang digunakan adalah Metode Pengamatan Langsung dari Konstruksi Dermaga dan Pemodelan Struktur dengan menggunakan FEA. Model akan dibuat menjadi 2 bentuk kondisi posisi Crane dan Trailer yang kemudian akan dianalisis hasil gaya-gaya yang terjadi dari setiap kondisi pendekatannya. Berdasarkan metode tersebut, penelitian ini memberikan kesimpulan bahwa, Crane dengan kapasitas 165 Ton dan Trailer tersebut tidak dapat dipergunakan bersamaan di atas Dermaga, serta melakukan kegiatan bongkar muat Pipa. Hal ini disebabkan oleh, terjadinya kegagalan sistem balok di bawah lantai Dermaga, walaupun kondisi Deformasi dan Tegangan Kompresi masih dalam batas aman. Sedangkan dari pengamatan visual menunjukkan beberapa kerusakan fatal dari sistem Balok, Pile Cap dan Pelat Lantai Dermaga berupa retakan besar yang memberikan dampak korosi tinggi pada elemen tulangan baja. Oleh sebab itu, Dermaga IV perlu untuk diberikan Revitalisasi Konstruksi untuk dapat melayani kegiatan bongkar muat dengan maksimal.
\end{abstract}

Kata kunci: Dermaga, FEA, Pelabuhan, Tarakan, Wilayah Pesisir. 


\section{Pendahuluan}

\subsection{Latar Belakang}

Konstruksi Dermaga yang telah berumur kurang lebih 40 tahun berada di Pelabuhan Malundung Kota Tarakan akan dipergunakan sebagai daerah bongkar muat pipa gas, sebelum pipa gas didistibusikan ke beberapa titik pengeboran. Salah satu metode bongkar muat yang diajukan oleh pihak suplai material adalah dengan meletakkan Mobil Crane pada bagian atas Dermaga, tentu saja hal ini memberikan kekhawatiran bagi pihak pengelola Pelabuhan tersebut, terkait keamanan dari Konstruksi Dermaga yang dimiliki, terlebih lagi kapasitas Mobil Crane yang digunakan sebesar 165 Ton.

Berdasarkan hal tersebut, dalam penelitian ini mencoba untuk menawarkan solusi alternatif dalam pengambilan keputusan metode yang digunakan untuk bongkar muat, yang tentunya berdasarkan kajian ilmiah berdasarkan keilmuan Teknik Sipil, Metode analisis yang digunakan adalah FEA yang dikombinasikan dengan pengamatan visual, dengan memodelkan konstruksi Dermaga pada skala 1 : 1, posisi Mobil Crane akan dipindahkan dan diasumsikan sebagai beban terpusat. Beban-beban yang bekerja akan dimodelkan sesuai dengan data-data yang diberikan oleh pihak pengguna Dermaga agar mendapatkan pendekatan yang lebih optimal.

Research GAP dalam penelitian ini adalah, dapat memberikan solusi terbaik dari kasus yang terjadi, dengan tinjauan analisis kekuatan konstruksi Dermaga yang dipecahkan dengan metode FEA, serta ditinjau dengan pengamatan fisik dari kondisi konstruksi Dermaga. Sehingga, dapat memberikan informasi dari pendekatan ilmiah terkait kekuatan Struktur Dermaga, sebagai pertimbangan dalam pengambilan keputusan yang akan dilakukan oleh pihak pengelola dan pihak pengguna Pelabuhan. Agar dapat memberikan hasil yang akurat, dalam penelitian ini diberikan beberapa batasan-batasan, yaitu : Data geomtrik Dermaga menggunakan data pendekatan dari posisi Dermaga III ; Data mutu material beton yang digunakan dalam pemodelan merupakan data autentik dilapangan saat ini ; Data mutu material baja untuk tulangan beton yang akan digunakan dalam pemodelan diambil dari kondisi normal mutu baja tulangan untuk pelabuhan, namun dikurangi dengan pertimbangan dugaan korosi yang terjadi pada material tulangan baja ; Pemodelan dan analisis dilakukan dengan metode FEA dengan bantuan perangkat lunak SAP2000 ; Tidak dilakukannya kajian konvergensi dan validasi pada model FEA yang dibuat untuk menganalisis perilaku Struktur Dermaga Pelabuhan, dikarenakan keterbatasan waktu dan anggran dalam penelitian.

\subsection{Tinjauan Pustaka}

Menurut Triatmojo. B (2010) dalam bukunya, menjelaskan bahwa Dermaga merupakan suatu bangunan pelabuhan yang digunakan untuk merapat dan menambatkan kapal yang melakukan bongkar muat barang dan menaik-turunkan penumpang. Bentuk dan dimensi Dermaga tergantung pada jenis dari ukuran kapal yang bertambat pada Dermaga tersebut. Struktur Dermaga terbagi menjadi 3 tipe dimana dibedakan menjadi bentuk Struktur Terbuka dan Struktur Tertutup. Pada daerah-daerah perairan tertentu juga sering ditemui Struktur Dermaga yang bukan termasuk dalam tipe tersebut, yaitu Struktur Dermaga Terapung (Floating Port), seperti yang banyak dipergunakan pada daerah perairan yang memiliki gelombang kecil, seperti di daerah pedalaman Kalimantan Utara.

Menurut Utomo. E (2018), menjelaskan bahwa Floating Port merupakan Barge yang terbuat dari kotak baja atau beton yang dapat mengapung menyesuaikan perubahan elevasi muka air laut. Barge dan daratan dihubungkan dengan Jetty. Triatmojo. B (2010) menjelaskan bahwa Dermaga Terapung digunakan pada daerah perairan yang memiliki pasang surut tinggi, berkisar 4 sampai 5 meter. 


\subsection{Beban Pada Dermaga}

Dermaga yang merupakan suatu bangunan sipil diciptakan berdasarkan fungsinya, tentu saja akan mengalami kontak langsung dengan alam yang akan menjadi beban yang harus dipikul oleh Struktur Dermaga, selain dari beratnya sendiri. Adapun pembebanan yang terjadi pada Dermaga diuraikan sebagai berikut :

\subsubsection{Beban Muatan Tetap}

Menurut Utomo.E (2018) muatan tetap suatu Dermaga merupakan beban yang tidak dapat berpindah dengan sendirinya dan atau beban yang memang sengaja diciptakan pada posisi tertentu pada suatu Dermaga untuk menunjang fungsi dari Dermaga itu sendiri, seperti seluruh elemen struktur pada konstruksi Dermaga, yaitu : Pelat lantai Dermaga, Pile Cap, Sistem-sistem balok, Tiang pancang, dan sebagainya. Beban muatan ini dapat diperkirakan dengan menghitung volume dari seluruh komponen pada konstruksi Dermaga dan mengkalinya dengan berat jenis dari masing-masing material pembentuknya.

Dalam era sekarang, muatan tetap sudah dapat diprediksikan secara otomatis melalui metode pemodelan, yaitu dengan memodelkan suatu konstruksi secara utuh dan berskala $1: 1$ maka seluruh berat dari suatu struktur akan otomatis dapat terditeksi.

\subsubsection{Beban Muatan Hidup}

Muatan hidup suatu Dermaga terbagi menjadi dua bagian, yaitu muatan beban yang diberikan oleh Manusia dalam penggunaanya dan muatan beban dari berbagai macam peralatan yang digunakan di atas lantai Dermaga untuk melaksanakan fungsinya. Menurut PPIUG (1987), perkiraan muatan hidup ada suatu lantai konstruksi yang disebabkan oleh Manusia dan barang bawaannya, yaitu sebesar 100 $\mathrm{kg} / \mathrm{m}^{2}$.

Salah satu muatan hidup lain yang paling sering digunakan dalam pelaksanaan bongkar muat di Dermaga adalah penggunaan Mobil Trailer. Mobil Trailer merupakan Truck angkutan terbuka yang dipergunakan untuk mengangkut muatan dari kapal menuju ketempat penyimpanan. Mobil Trailer memiliki banyak jenis berdasarkan fungsinya masing-masing. Mobil Trailer yang digunakan dalam penelitian ini merupakan Trailer terbuka untuk pengangkutan Pipa Baja, sehingga memiliki spesifikasi khusus. Seperti yang ditunjukkan pada Tabel 1 berikut ini :

Tabel 1. Data Mobil Trailer

\begin{tabular}{cc}
\hline \multicolumn{1}{c}{ Keterangan } & Nilai \\
\hline Prime Mover & $10.320 \mathrm{~kg}$ \\
$\bullet$ Berat Kosong & $6.630 \mathrm{~mm}$ \\
$\bullet$ Panjang & $2.500 \mathrm{~mm}$ \\
- Lebar & $2.850 \mathrm{~mm}$ \\
Tinggi & $180 \mathrm{~kg}$ \\
Trailer Daya Angkat & \\
$\bullet \quad$ Berat Kosong & $11.250 \mathrm{~kg}$ \\
- Panjang & $12.200 \mathrm{~mm}$ \\
$\bullet \quad$ Tinggi & $2.500 \mathrm{~mm}$ \\
- Daya Angkut & $1.500 \mathrm{~mm}$ \\
Total Berat Kendaraan Mobil Trailer & $25.320 \mathrm{~kg}$ \\
\hline
\end{tabular}

Sumber: PT. Altus Logistics Servies Indonesia 
Transfer pembebanan dari Mobil Trailer juga akan berbeda disetiap roda mobil yang akan bersentuhan langsung dengan pelat lantai Dermaga. Hal ini telah diataur dalam prosentasre transfer beban ke roda yang dikeluarkan oleh Ditjen Bina Marga, No.01/MN/BM/1983 dan Permenhub (Peraturan Menteri Perhubungan No.14 tahun 2007, dengan rincian transfer beban ditunjukkan pada Tabel 2 berikut ini :

Tabel 2. Prosentase Transfer Beban Roda Mobil Trailer

\begin{tabular}{cr}
\hline \multicolumn{1}{c}{ Keterangan } & Nilai \\
\hline Total Berat Mobil Trailer & 47,07 Ton \\
Prosentase Pembagian Beban : & \\
- Roda Depan Prime Move ; 13\% & 6,12 Ton \\
- Roda Belakang Prime Move ; 40\% & 18,83 Ton \\
- Roda Belakang Trailer ; 47\% & 22,12 Ton \\
Transver Beban Pada setiap Roda : & \\
- Roda Depan Prime Move ; 2 Roda (P1) & 2,06 Ton (1 Roda) \\
- Roda Belakang Prime Move ; 4 Roda (P2) & 4,71 Ton (1 Roda) \\
Jarak As antar Roda : & 3,69 Ton (1 Roda) \\
- P1 ke P1a & \\
- P1a ke P1b & $4.000 \mathrm{~mm}$ \\
- P1b ke P2b $\quad$ P2a ke P2b & $1.250 \mathrm{~mm}$ \\
- P2b ke P2c & $9.000 \mathrm{~mm}$ \\
\end{tabular}

Sumber: Analisis Penelitian

Selain Mobil Trailer, peralatan lain yang kerap digunakan adalah Mobil Crane, adapun spesifikasi Crane yang dipergunakan dalam rencana bongkar muat ditunjukkan pada Tabel 3 berikut ini :

Tabel 3. Spesifikasi Data Mobil Crane

\begin{tabular}{cr}
\hline \multicolumn{1}{c}{ Keterangan } & Nilai \\
\hline Berat Mobil Crane : & 65 Ton \\
- Muatan Kosong Crane & 100 Ton \\
- Muatan isi Crane & 165 Ton \\
Spesifikasi Cadik / Jacking Crane: & \\
- Jumlah Cadik & $4 \mathrm{Titik}$ \\
- Jarak Melintang & $7.200 \mathrm{~mm}$ \\
Transver Beban Pada Cadik Asumsi Seimbang & $8.814 \mathrm{~mm}$ \\
- Setiap Cadik Memberikan Beban & \\
\hline
\end{tabular}

Sumber: PT. Altus Logistics Servies Indonesia

Selain menerima muatan hidup yang berposisi di atas lantai, Dermaga juga akan menerima bebanbeban horizontal dari peralatan lain, yaitu dari kapal. Adapun kapal yang digunakan dalam penelitian ini adalah Supply Boat, dengan spesifikasi seperti yang ditunjukkan pada Tabel 4.

\subsubsection{Beban Muatan Lingkungan}

Dermaga secara harfiahnya akan berkontak langsung dengan lingkungan, dimana bagian lingkungan yang memberikan dampak signifikan adalah wilayah perairan. Wilayah perairan tentu saja terdiri dari berbagai variabel yang berperan dalam memberikan beban, diantaranya adalah Angin dan 
Gelombang. Utomo.E (2018) dalam penelitiannya menyebutkan beberapa nilai yang dapat digunakan sebagai acuan untuk menggambarkan beban di wilayah perairan Kota Tarakan, Seperti : Tinggi Pasang Surut berkisar antara 5,00 Meter, Kecepatan Angin Maksimum 25 knots dengan Tekanan $39,375 \mathrm{~kg} / \mathrm{m}^{2}$, Kecepatan arus perairan maksimum 1,00 m/s, dan Berat jenis air laut sebesar $1,03 \mathrm{Ton} / \mathrm{M}^{3}$.

Tabel 4. Spesifikasi Data Supply Boat

\begin{tabular}{|c|c|}
\hline Keterangan & Nilai \\
\hline \multicolumn{2}{|l|}{ Spesifikasi Dimensi Kapal : } \\
\hline - LOA, (Length Over All) & 70,00 Meter \\
\hline - LPP, (Length Between Perpendicular) & 65,00 Meter \\
\hline - $\quad \mathrm{B}$, (Width Total) & 17,00 Meter \\
\hline - $\mathrm{T},($ Draft $)$ & 2,26 Meter \\
\hline - $\mathrm{H},($ Height Total $)$ & 3,69 Meter \\
\hline - DWT, Bobot Muatan Kapal & 900 Ton \\
\hline - LWT, Bobot peralatan \& Konstruksi Kapal & 385,71 Ton \\
\hline - $\quad \Delta$, Displacement Full Load & $1.285,71$ Ton \\
\hline - Vs, Kecepatan Rancang Kapal & $13,00 \mathrm{Knot}$ \\
\hline \multicolumn{2}{|l|}{ Koefisien : } \\
\hline - $\quad \mathrm{Cb},($ Koefisien Blok) & 0,50 \\
\hline - $\quad \mathrm{Cm}$, (Koefisien Massa) & 1,42 \\
\hline - 1 , jarak pusat berat kapal ke titik sandar & 17,50 Meter \\
\hline - $r$, jari-jari putaran & 14,35 Meter \\
\hline - Ce, Koefisien Eksentrisitas & 0,40 \\
\hline - Cs, Koefisien \& Cc, Koefisien Bentuk & 1,00 \\
\hline
\end{tabular}

Sumber: Analisa Penelitian

\subsubsection{Beban Benturan Dan Tarikan Dari Fungsi Dermaga}

Tiratmojo. B (2010) memberikan pendekatan persamaan untuk dapat memperkirakan gaya yang bekerja bergantung pada Kapal yang bersandar pada suatu Dermaga. Adapun persamaan Energi benturan ditunjukkan pada persamaan berikut ini :

$$
E=\frac{W V^{2}}{2 g} C_{m} C_{e} C_{s} C_{c}
$$

Dimana :

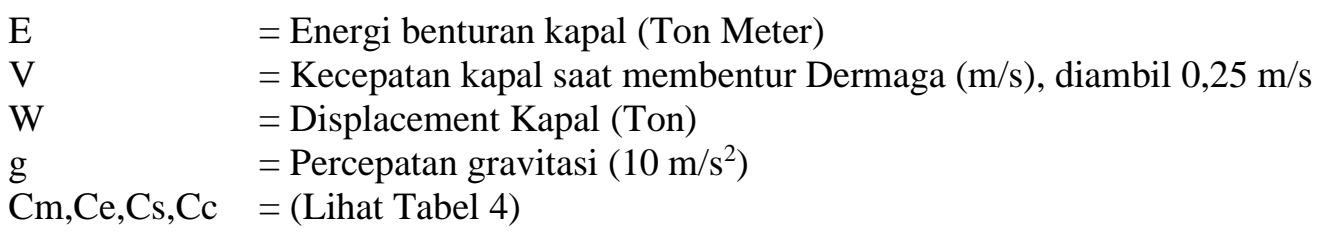

Sedangkan gaya akibat tambatan kapal pada Dermaga atau yang dikenal sebagai (Mooring Force), terdiri dari 2 gaya, yaitu gaya akibat angin dan gaya akibat arus. Gaya yang diakibatkan oleh angin dapat ditentukan dengan menggunakan persamaan sebagai berikut :

$$
\begin{aligned}
& \alpha=0^{\circ} ; R_{w}=0,42 P_{a} A_{w} \\
& \alpha=180^{\circ} ; R_{w}=0,50 P_{a} A_{w} \\
& \alpha=90^{\circ} ; R_{w}=1,1 P_{a} A_{w}
\end{aligned}
$$

Dimana : 
$\mathrm{Rw} \quad=$ Gaya akibat angin, $(\mathrm{kg})$

$\mathrm{Pa} \quad=$ Tekanan angin, ditentukan dengan $0,063 \mathrm{~V}^{2},\left(\mathrm{~kg} / \mathrm{m}^{2}\right)$

$\mathrm{V}=$ Kecepatan angin, $(\mathrm{m} / \mathrm{s})$

Aw $\quad=$ Proyeksi bidang yang tertiup angin, ditentukan $70 \%$ dari luas bagian kapal diatas garis air, $\left(\mathrm{m}^{2}\right)$

Sedangkan gaya tarik akibat arus diambil dari bagian kapal yang terendam air. Besarnya gaya yang ditimbulkam oleh arus dapat diperkirakan dengan menggunakan persamaan berikut ini :

$$
R_{a}=C_{C} \cdot \rho \cdot A_{C} \cdot\left(\frac{V_{C}{ }^{2}}{2 g}\right)
$$

Dimana :

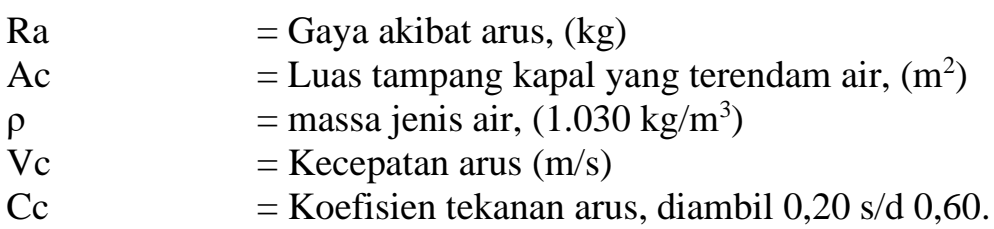

\subsubsection{Beban Akibat Gaya Gempa}

Gaya eksternal lain dari lingkungan yang memungkinkan terjadi adalah gaya akibat gempa. Gaya gempa dalam pemodelan FEA dapat dimodelkan dengan menggunakan pendekatan Respons Spectrum gempa yang mangacu pada koefisien gempa dasar dari letak konstruksi bangunan pada peta zonasi gempa, baik pada periode pendek maupun periode panjang. Dalam penelitian ini data gempa menggunakan pendekatan yang telah tersedia di situs laman PUSKIM LITBANG PU, puskim.pu.go.id. Adapaun letak koordinat posisi Dermaga adalah, Lintang 3,2821839284 dan Bujur 117,592429502. Hal lain yang menjadi inputan data untuk analisis Respons Spectrum diperkirakan, hal ini dilakukan karena kurangnya biaya dan waktu untuk pengambilan data melalui soil investigation. Berikut ini ditunjukkan Spektrum Desain yang telah dikalkulasi dari PUSKIM LITBANG PU pada posisi Dermaga :

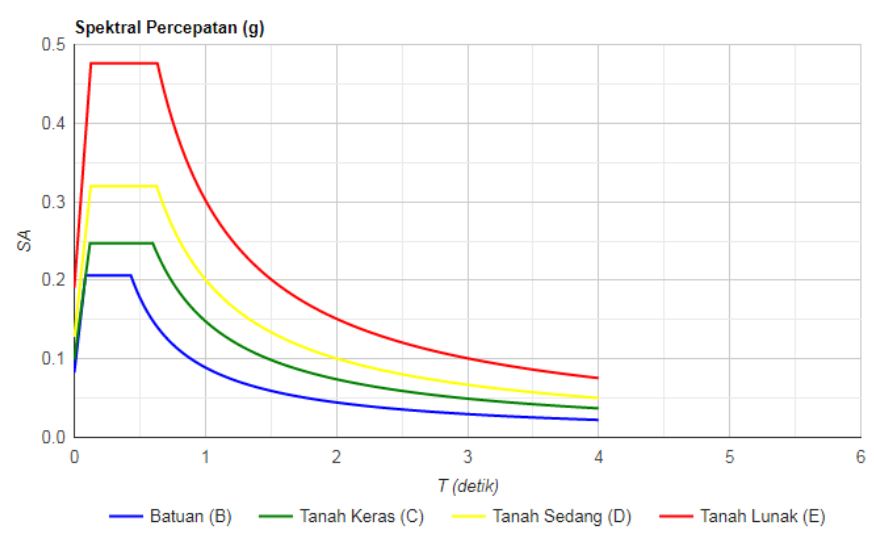

Gambar 1 : Spektrum Respons Design Posisi Dermaga IV Pelabuhan Malundung

Adapun parameter nilai-nilai gempa untuk analisis Respons Spectrum gempa adalah sebagai berikut:

1. Respons Spektra 0,2 detik probabilitas $2 \%(\mathrm{Ss})=0,305$

2. Respons Spektra 1 detik Probabilitas $2 \%(\mathrm{~S} 1)=0,132$

3. Parameter Jenis Tanah, (Asumsi Lunak) $; \mathrm{Fa}=2,323$ 
4. Parameter Jenis Tanah, (Asumsi Lunak); $\mathrm{Fv} \quad=3,403$

5. Parameter Kecepatan Spektrum, $\left(\mathrm{S}_{\mathrm{DS}}\right) \quad=0,299$

6. Skala Faktor Keutamaan, (Asumsi) $\quad=1,839$

\subsubsection{Kombinasi Pembebanan}

Banyaknya muatan beban yang memberikan pengaruh kepada kekuatan struktur Dermaga, maka seluruh beban haruslah dikombinasikan, sehingga dapat diketahui kondisi perilaku optimum yang memungkinkan akan terjadi untuk menggambarkan kondisi sesungguhnya. Adapun beberapa perkiraan kombinasi pembebanan yang diperkirakan dalam SNI Pembebanan adalah sebagai berikut:

1. $\mathrm{COMB} .1=1,4 \mathrm{DL}$

2. $\mathrm{COMB} \cdot 2=1,2 \mathrm{DL}+1,6 \mathrm{LL} \cdot \mathrm{A}$

3. COMB. $3=1,2 \mathrm{DL}+1,6 \mathrm{LL} \cdot \mathrm{A}+1,6 \mathrm{BF}$

4. $\mathrm{COMB} .4=1,2 \mathrm{DL}+1,6 \mathrm{LL} \cdot \mathrm{A}+1,6 \mathrm{MF}$

5. COMB.5 $=1,2 \mathrm{DL}+1,6 \mathrm{LL} \cdot \mathrm{A}+1,6 \mathrm{LL} \cdot \mathrm{B}$

6. COMB. $6=1,2 \mathrm{DL}+1,6 \mathrm{LL} \cdot \mathrm{A}+1,6 \mathrm{LL} \cdot \mathrm{B}+1,6 \mathrm{LL} \cdot \mathrm{C}$

7. COMB.7 $=1,2 \mathrm{DL}+1,6 \mathrm{LL} \cdot \mathrm{A}+1,6 \mathrm{LL} \cdot \mathrm{B}+1,6 \mathrm{BF}$

8. COMB. $8=1,2 \mathrm{DL}+1,6 \mathrm{LL} \cdot \mathrm{A}+1,6 \mathrm{LL} \cdot \mathrm{B}+1,6 \mathrm{MF}$

9. COMB.9 $=1,2 \mathrm{DL}+1,6 \mathrm{LL} \cdot \mathrm{A}+1,6 \mathrm{LL} \cdot \mathrm{B}+1,6 \mathrm{LL} \cdot \mathrm{C}+1,6 \mathrm{BF}$

10.COMB. $10=1,2 \mathrm{DL}+1,6 \mathrm{LL} \cdot \mathrm{A}+1,6 \mathrm{LL} \cdot \mathrm{B}+1,6 \mathrm{LL} \cdot \mathrm{C}+1,6 \mathrm{MF}$

11. COMB. $11=0,90 \mathrm{DL}+1,0 \mathrm{Ex}$

12. $\mathrm{COMB} \cdot 12=0,90 \mathrm{DL}+1,0 \mathrm{Ey}$

13.COMB. $13=1,0 \mathrm{DL}+0,5 \mathrm{LL} \cdot \mathrm{A}+1,0 \mathrm{LL} \cdot \mathrm{B}+1,0 \mathrm{Ex}$

14.COMB. $14=1,0 \mathrm{DL}+0,5 \mathrm{LL} \cdot \mathrm{A}+1,0 \mathrm{LL} \cdot \mathrm{B}+1,0 \mathrm{Ey}$

15. COMB. $15=1,2 \mathrm{DL}+1,6 \mathrm{LL} \cdot \mathrm{A}+1,6 \mathrm{LL} \cdot \mathrm{B}+1,6 \mathrm{LL} \cdot \mathrm{C}+1,6 \mathrm{MF}+1,6 \mathrm{BF}+1,0 \mathrm{Ex}$

16. COMB. $16=1,2 \mathrm{DL}+1,6 \mathrm{LL} \cdot \mathrm{A}+1,6 \mathrm{LL} \cdot \mathrm{B}+1,6 \mathrm{LL} \cdot \mathrm{C}+1,6 \mathrm{MF}+1,6 \mathrm{BF}+1,0 \mathrm{Ey}$

17.COMB. $17=1,2 \mathrm{DL}+1,6 \mathrm{LL} \cdot \mathrm{A}+1,6 \mathrm{LL} \cdot \mathrm{B}+1,6 \mathrm{LL} \cdot \mathrm{C}+1,6 \mathrm{BF}+1,6 \mathrm{MF}$

Keterangan :

DL = Dead Load, (Muatan Tetap / Berat Struktur Dermaga)

LL.A = Live Load, (Muatan Hidup, Manusia)

LL.B = Live Load, (Muatan Hidup, Mobil Trailer)

LL.C = Live Load, (Muatan Hidup, Mobil Crane)

$\mathrm{BF}=$ Breathing Force, (Gaya Sandar Kapal)

MF = Mooring Force, (Gaya Tarik / Tambat Kapal)

$\mathrm{Ex} \quad=$ Gempa Arah X

Ey $\quad=$ Gempa Arah Y

Kombinasi pembebanan diperkirakan sebanyak 17 kemungkinan kombinasi yang memungkinkan dapat mewakili pendekatan kondisi pembebaban aktual dilapangan dari berbagai aspek beban. Selain itu, kombinasi pembebanan juga merepresentasikan bentuk dan pola pengoperasian Dermaga Pelabuhan yang lebih aman untuk digunakan sesuai dengan input data pembebanan yang diasumsikan. 


\section{Metode Penelitian}

\subsection{Alur Penelitian}

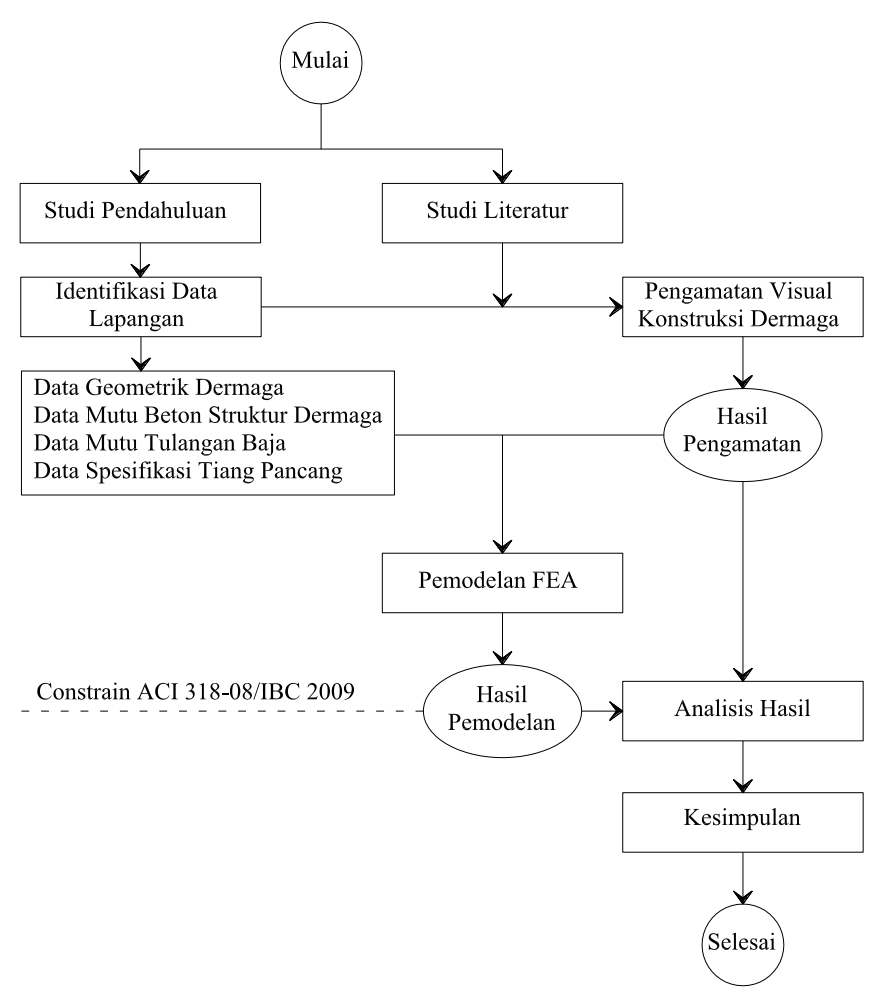

\section{Gambar 2 : Skema Penelitian}

\subsection{Identifikasi Data Lapangan}

Identifikasi data lapangan dilakukan untuk mendapatkan informasi kondisi dan geometrik ukuran Dermaga, yang nantinya data-data ini akan menjadi data input dalam pemodelan konstruksi Dermaga. Beberapa data yang diperkirakan wajib untuk ada antara lain sebagai berikut :

1. Dimensional Dermaga, pengambilan data pengukuran langsung dan validasi melalui As Built Drawing Konstruksi Dermaga.

2. Konfigurasi elemen Struktur, pengambilan data pengukuran langsung di lokasi Dermaga.

3. Kedalaman Pemancangan, pengambilan data berdasarkan pendekatan dari As Built Drawing Konstruksi Dermaga.

4. Material, menggunakan data aktual yang terjadi dilapangan, pengambilan data menggunakan metode Non-destructive test dengan alat uji Ribbon Hammer Test untuk pengambilan sampel mutu beton.

\subsection{Pengamatan Visual Konstruksi Dermaga}

Tahap pengamatan visual memiliki peranan penting dalam penelitian ini. Hasil pengamtan ini dipergunakan untuk memperkirakan atau menilai secara visual kondisi kerusakan konstruksi bila terjadi, dan menjadi dasar peneliti dalam memberikan justifikasi pada Tahap pemodelan FEA dan pengambilan keputusan. Data tersebut menjadi acuan dalam pemodelan FEA yang akan dipergunakan dalam analisis kekuatan struktur Dermaga. Adapun batasan atau target nilai kekuatan yang diharapkan adalah mengacu pada ACI 318-08 / IBC 2009, yang sudah terdapat pada perangkat lunak pemodelan FEA. 


\subsection{Tahap Analisis Hasil}

Analisis hasil yang dilakukan pertama kali adalah justifikasi teknis dari hasil pengamatan visual konstruksi Dermaga, yang kemudian dilanjutkan perkiraan kemungkinan kegagalan struktur akan terjadi pada bagian elemen yang mana pada Konstruksi Dermaga. Selanjutnya analisis hasil juga menganalisa dari hasil kerusakan yang ditunjukkan oleh program FEA.

Tahapan analisis hasil juga menganalisis dari hasil kerusakan yang ditunjukkan oleh Program FEA. Maka, dapat disimpulkan bahwa tahapan analisis hasil ini, dari dua metode yang digunakan adalah saling berhubungan. Selain itu, dalam pemodelan yang juga akan mensimulasikan kombinasi pembebanan berdasarkan fungsional Dermaga. Hal ini juga akan dianalisis untuk mengetahui pada kombinasi pembebanan atau pada kegiatan apa yang melibatkan pembebanan pada strktur akan berkontribusi memberikan kerusakan atau kegagalan pada konstruksi Dermaga. Adapun parameter hasil yang akan dinilai yaitu, Nilai Deformasi maksimum yang terjadi, Nilai Compresive Stress, Nilai Axial Load pada tiang pancang dan Momen yang mengakibatkan Crack pada tiang pancang.

\section{Hasil dan Pembahasan}

\subsection{Hasil Pengamatan Visual}

Berdasarkan hasil pengamatan visual yang dilakukan, beberapa kerusakan terjadi pada komponen struktur Dermaga. Beberapa bagian pelat mengalami keretakan, diperkirakan terjadinya retakan bukan akibat kegagalan struktur, melainkan berasal dari pola yang dihasilkan oleh pelapisan bekisting dengan plastik pada proses pekerjaan dilaksanakan.

Berbeda dengan kerusakan komponen struktur pada Pile Cap Dermaga. Keretakan yang terjadi diprediksikan karena kelelahan struktur dan pembebanan impact dari Breathing Force, Mooring Force dan beban-beban vertikal dari atas Dermaga yang telah berulang. Over kapasitas pembebanan yang telah terjadi selama kurun waktu umur konstruksi tersebut menghasilkan tegangan yang tersimpan pada struktur Pile Cap. Hal ini akan berpengaruh pada kualitas struktur Dermaga, Bahkan akan mengalami kegagalan konstruksi jika Dermaga dipaksakan menerima beban melampaui kapasitasnya saat ini.

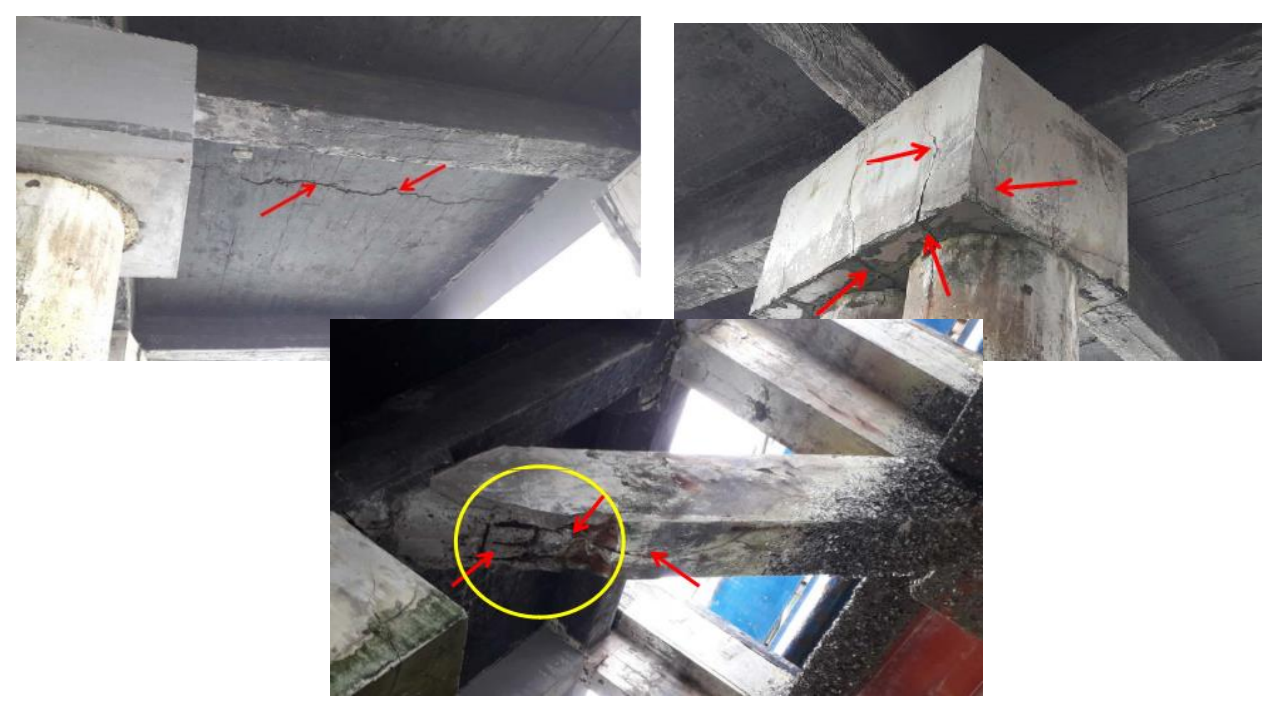

Gambar 3 : Pola Keretakan yang terjadi pada Sturktur Bawah Konstruksi Dermaga 
Keretakan lainnya terjadi pada balok penyokong beban lateral, yang menghubungkan konstruksi sisi depan Dermaga dengan tiang pancang dibelakangnya. Balok ini dibuat untuk mentransferkan beban Breathing Force dan Mooring Force pada Dermaga. Pengulangan beban yang terus menerus selama umur konstruksi mengakibatkan keretakan menjadi melebar dan mengalami kepecahan pada balok di bagian tumpuan atas. Hal ini mengakibarkan tereksposnya tulangan baja yang berada dalam beton, sehingga tidak ada lagi cover pelindung tulangan agar terjaga dari korosi yang terjadi.

Korosi yang terjadi pada tulangan baja tersebut terus terjadi karena tidak dilakukannya perbaikan pada saat kepecahan terjadi pada balok, mengingat sulitnya area untuk melakukan monitoring pada bagian bawah lantai Dermaga. Sehingga, korosi yang terjadi semakin menyebar sampai mengurangi luas penampang dari baja tulangan. Hal ini juga dapat mengakibatkan perambatan atau laju korosi semakin menyebar sampai pada tulangan baja yang masih terselimuti oleh beton. Jika hal tersebut terjadi, maka kualitas tulangan baja akan menurun yang mengakibatkan balok dalam kondisi kritis.

Hasil pengamatan visual ini sangat memberikan kekhawatiran jika lantai Dermaga tetap dipergunakan, terlebih lagi pada pembebanan yang melebihi kapasitas awal. Hal ini perlu mendapatkan perhatian khusus oleh pengelola dan pengguna pelabuhan, untuk dapat melakukan perbaikan, pengurangan kapasitas kerja Dermaga Pelabuhan atau Pembongkaran pada Dermaga jika memang hasil analisis lebih lanjut menyatakan akan terjadi kegagalan struktur.

\subsection{Hasil Pemodelan Dermaga Model.1 (Crane Sisi Kanan)}

Berdasarkan pemodelan yang dilakukan, pada kondisi pemodelan Model.1 dimana posisi Crane dan Trailer berada pada skema sisi kanan, maka didapatkan hasil sebagai berikut :

1. Deformasi titik strktur terbesar adalah $22,049 \mathrm{~mm}$. Nilai perpindahan ini cukup kecil dan Dermaga tidak megalami pergoyangan yang signifikan.

2. Tegangan tekan pada pelat lantai Dermaga maksimum $21,221 \mathrm{Mpa}$. Nilai ini masih di bawah dari nilai kuat tekan beton lantai Dermaga yaitu 42,28 Mpa. Hal ini menunjukkan bahwa tidak terjadi kegagalan pada bagian pelat lantai Dermaga.

3. Pada sistem balok beberapa kombinasi pembebanan menunjukkan ketidakstabilan struktur balok. Seluruh balok mengalami kegagalan adalah balok disekitar posisi Crane. Kegagalan balok diakibatkan berlebihnya tegangan geser dan torsi pada balok tersebut.

4. Nilai Momen dan Axial Load pada tiang pancang masih di bawah dari nilai yang ditetapkan sebagai batasan. Maka pancang masih dalam range aman.

\subsection{Hasil Pemodelan Dermaga Model.2 (Crane Tengah)}

Berdasarkan pemodelan yang dilakukan, pada kondisi pemodelan Model.2 dimana posisi Crane dan Trailer berada pada skema tengah Dermaga, maka didapatkan hasil sebagai berikut :

1. Deformasi titik strktur terbesar adalah $20,331 \mathrm{~mm}$. Nilai perpindahan ini cukup kecil dan Dermaga tidak megalami pergoyangan yang signifikan.

2. Tegangan tekan pada pelat lantai Dermaga maksimum 17,609 Mpa. Nilai ini masih di bawah dari nilai kuat tekan beton lantai Dermaga yaitu 42,28 Mpa. Hal ini menunjukkan bahwa tidak terjadi kegagalan pada bagian pelat lantai Dermaga.

3. Pada sistem balok beberapa kombinasi pembebanan menunjukkan ketidakstabilan struktur balok. Seluruh balok mengalami kegagalan adalah balok disekitar posisi Crane. Kegagalan balok diakibatkan berlebihnya tegangan geser, lentur dan torsi pada balok tersebut. 
4. Nilai Momen dan Axial Load pada tiang pancang masih di bawah dari nilai yang ditetapkan sebagai batasan. Maka pancang masih dalam range aman.

\subsection{Hasil Perbandingan Analisis Model.1 dan Model.2}

Hasil Perbandingan Nilai Deformasi ditunjukkan dengan rincian dari setiap kombinasi pembebaban dan dari setiap Model perletakan Crane dan Trailer, seperti yang ditunjukkan pada Gambar 4 berikut ini :

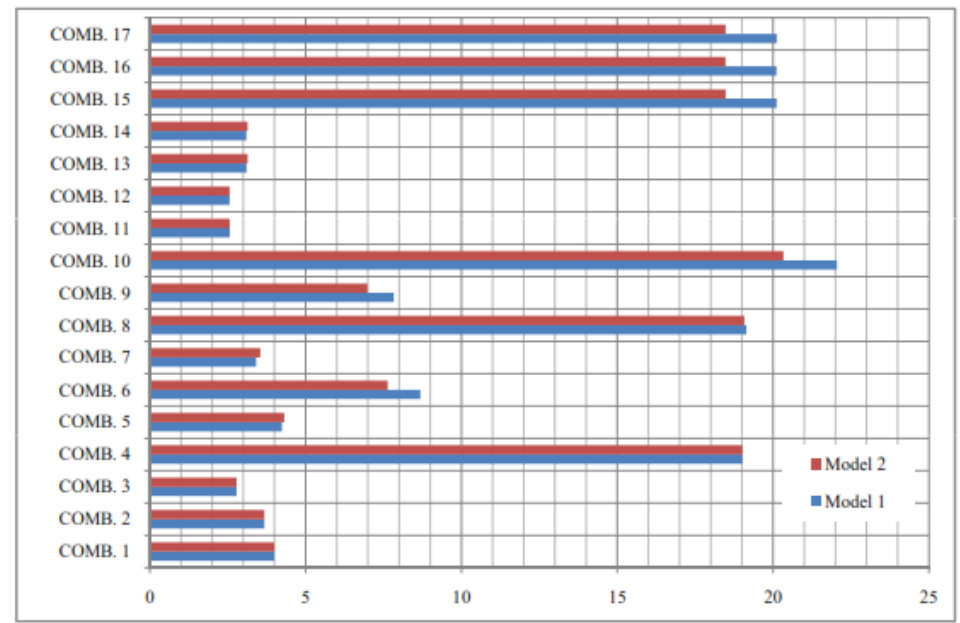

Gambar 4 : Diagram Perbandingan Nilai Deformasi Tiap Model Dermaga

Pada diagram ini menunjukkan perubahan nilai deformasi pada komponen struktur Dermaga antara Model.1 dan Model.2. Beberapa pemodelan beban yang tidak memiliki komponen Crane dan Trailer di dalamnya menghasilkan deformasi yang kecil. Namun, setelah Crane dan Trailer dioperasikan, maka terjadi peningkatan deformasi yang signifikan pada kedua Model. Peningkatan deformasi ini menunjukkan bahwa penggunaan Crane dengan kapasitas total 165 Ton memberikan dampak yang besar pada struktur Dermaga, begitu juga dengan penggunaan Trailer untuk muatan Pipa, walaupun nilai deformasi yang dihasilkan tidak mecapai $5 \mathrm{~cm}$.

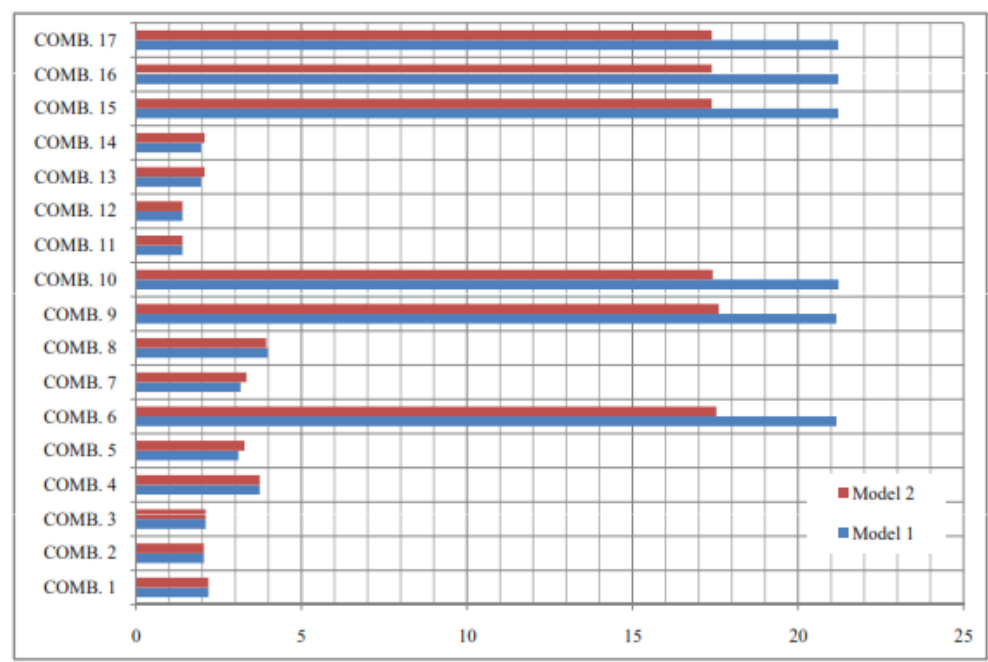

Gambar 5 :Diagram Perbandingan Comphresive Stress Tiap Model Dermaga 
Tinjauan lainnya adalah dengan memperhatikan perubahan nilai tekanan pada lantai Dermaga, yang ditunjukkan pada Diagram Gambar 5. Tekanan pada lantai Dermaga juga mengalami peningkatan secara signifikan pada kombinasi pembebaban yang melibatkan Crane dan Trailer dengan kapasitas total 165 Ton pada lantai Dermaga. Nilai tegangan tekan pada lantai Dermaga juga mengalami perubahan ketika posisi Crane dan Trailer dirubah. Pada Model.2 posisi Crane dan Trailer diletakkan pada bagian tengah Dermaga terukur 2 meter dari sisi Bollard Dermaga, tekanan yang dihasilkan lebih rendah jika dibandingkan dengan Model.1 dimana Crane dan Trailer diposisikan pada sisi kanan Dermaga.

Walaupun deformasi dan tekanan kompresif pada pelat masih dalam batas kewajaran. Namun pada sistem balok terjadi masalah yang perlu menjadi perhatian. Seperti yang dapat dianalisa dari Gambar 6 berikut ini :

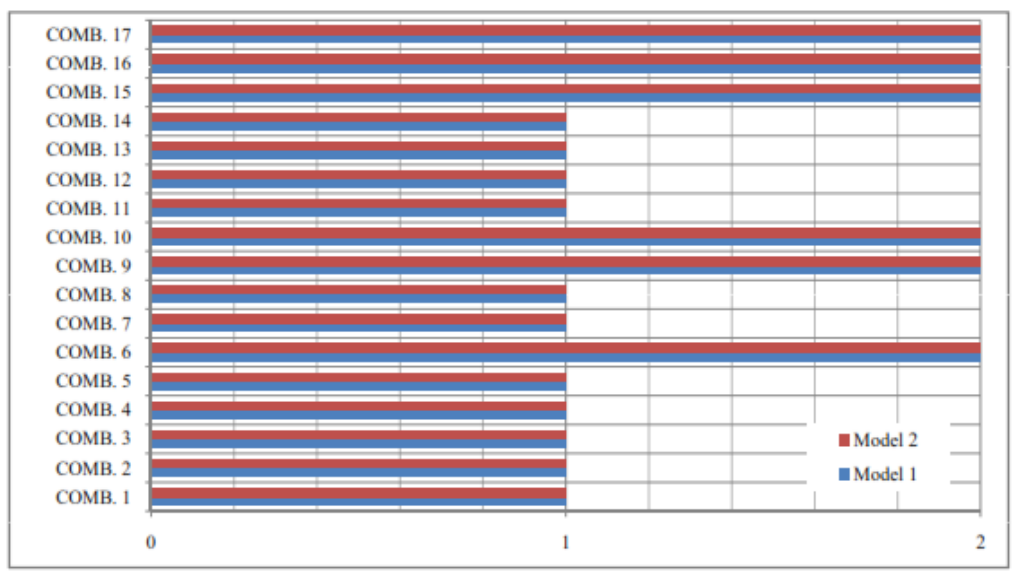

Gambar 6 :Diagram Perbandingan Kegagalan Sistem Struktur

Gambar 6 menunjukkan Diagram perbandingan dari kegagalan sistem struktur dari kedua Model yang dibuat. Skala 0 sampai dengan 1 menunjukkan tidak terjadinya kegagalan sistem balok di bawah lantai Dermaga, sedangkan untuk skala 0 sampai dengan 2 menunjukkan terjadinya kegagalan sistem balok di bawah lantai Dermaga.

Pada Model.1 kegagalan balok terjadi pada bagian balok yang terkena imbas langsung tekanan beban dari Crane dan Trailer, terlebih lagi pada saat kegiatan operasional bongkar muat dilakukan, pembebanan akan bertambah akibat adanya benturan (Breathing Force) dan gaya tambat (Mooring Force) dari kapal pada sisi Dermaga. Bentuk kegagalan balok ini adalah terjadinya tegangan geser dan torsi yang berlebihan, sehingga memungkinkan balok akan mengalami patah, untuk menghindari hal tersebut, maka sistem balok diperkirakan harus diperbesar.

Sama halnya dengan Model.1, pada Model.2 ketika posisi Crane dan Trailer dipindahkan pada bagian tengah Dermaga, hal serupa juga terjadi pada sistem balok, yaitu saat Crane dan Trailer membebani langsung lantai Dermaga, terlebih lagi jika dilakukan kegiatan bongkar muat pipa. Gaya benturan kapal dan tarikan tambatan kapal memberikan dampak kegagalan menjadi semakin besar pada sistem balok di bawah Crane. Namun, bentuk kegagalan ini berbeda dengan kegagalan pada Model.1, dimana pada Model.2 kegagalan balok cenderung terjadi pada kekuatan lentur balok (Flexural Strength) tegaangan lentur yang dihasilkan dari posisi Crane di tengah Dermaga sangat besar. Hal ini dapat dihindari dengan menambahkan sisem pembesian pada Balok atau memperbesar ukuran balok. 


\section{Kesimpulan}

Berdasarkan kajian penelitian ini, baik dari metode pengamatan visual dan metode analisis kekuatan dengan FEA yang dilakukan, dapat ditarik beberapa kesimpulan, diantaranya adalah sebagai berikut : Crane dengan Kapasitas total 165 Ton dan Trailer tidak dapat dipergunakan bersamaan di atas Dermaga, serta melakukan kegiatan bongkar muat pipa. Hal ini didasari bahwa terjadinya sistem balok di bawah lantai Dermaga. Apabila kegiatan bongkar muat tetap harus dilakukan di Dermaga IV, maka sebaiknya menggunakan sistem Barge atau Ponton dari sisi laut. Namun, memerlukan dukungan Buoy Mooring atau Fixed Mooring agar gaya Mooring dari Barge dan Kapal saat melakukan kegiatan tidak seluruhnya di terima oleh Struktur Dermaga. Berdasarkan pengamatan visual langsung pada konstruksi Dermaga, Kondisi saat ini banyak bagian Balok, Pile Cap, dan Pelat Lantai Dermaga mengalami keretakan besar, sehingga mengakibatkan korosi pada tulangan beton tidak dapat dihindari perambatannya, yang memberikan dampak pengurangan luasan tulangan beton, sehingga akan mengurangi kekuatan dari struktur Dermaga tersebut.

\section{Saran}

Demikian penelitian ini dibuat, penelitian ini dapat dipertanggung jawabkan kebenarnnya selama masih dalam batasan-batasan dalam kajian analisis yang dilakukan. Adapun beberapa saran yang dapat diberikan sebagai berikut :

1. Penelitian ini dapat menjadi dasar pengambilan keputusan kegiatan bongkar muat, terutama muatan pipa baja yang nantinya akan dilaksanakan di atas Dermaga IV Pelabuhan Malundung Kota Tarakan.

2. Perlunya analisis lanjutan untuk metode yang lebih tepat dalam pelaksanaan bongkar muat di atas Dermaga IV Pelabuhan Malundung Kota Tarakan.

\section{Daftar Pustaka}

Departemen Pekerjaan Umum (1987), "Perencanaan Pembebanan Untuk Rumah dan Gedung", SKBI - 1.3.53.1987, UDC : 624.042, Jakarta.

Graha Mitra Nusantasa. (2017), "Laporan Desain Struktur Pekerjaan Pemasangan Ponton Dermaga Tideng Pale, Kabupaten Tana Tidung.

Puskim Litbang PU (2019), 'Desain Spektra Indonesia’, puskim.pu.go.id.

SNI 1727. (2013), "Beban minimum untuk perancangan bangunan gedung dan struktur lain", Badan Standarisasi Nasional.

SNI 2847.(2013),"Persyaratan beton struktural untuk bangunan gedung”, Badan Standarisasi Nasional.

Triatmojo.B. (2009), ‘Perencanaan Pelabuhan', Yogyakarta, Beta Offset, hal 195-238.

Utomo. E. (2018), 'Perbandingan Desain Dermaga Terapung Pada Sistem Konstruksi Melintang dan Memanjang "Studi Kasus Dermaga Pelabuhan Tideng Pale Kabupaten Tana Tidung"', Borneo Engineering Jurnal Teknik Sipil, Vol.2 No.1, pp 1 -13. 
